Article

\title{
On-Line Organic Solvent Field Enhanced Sample Injection in Capillary Zone Electrophoresis for Analysis of Quetiapine in Beagle Dog Plasma
}

\author{
Yuqing Cao ${ }^{1,2,+}$, Jun Wen ${ }^{1,2,+}$, Tingting Zhou ${ }^{1,2, *}$ and Guorong Fan ${ }^{1,2,3, *}$ \\ Received: 9 December 2015 ; Accepted: 18 January 2016 ; Published: 21 January 2016 \\ Academic Editor: Derek J. McPhee \\ 1 Department of Pharmaceutical Analysis, School of Pharmacy, Second Military Medical University, \\ Shanghai 200433, China; caoyuqing1109@163.com (Y.C.); wenjunapple@163.com (J.W.) \\ 2 Shanghai Key Laboratory for Pharmaceutical Metabolite Research, Shanghai 200433, China \\ 3 Department of Clinical Pharmacy, Shanghai General Hospital, School of Medicine, \\ Shanghai Jiaotong University, No. 100 Haining Road, Shanghai 200025, China \\ * Correspondence: tingting_zoo@163.com (T.Z.); guorfan@outlook.com (G.F.); \\ Tel./Fax: +86-21-8187-1260 (G.F.) \\ + These authors contributed equally to this work.
}

\begin{abstract}
A rapid and sensitive capillary zone electrophoresis (CZE) method with field enhanced sample injection (FESI) was developed and validated for the determination of quetiapine fumarate in beagle dog plasma, with a sample pretreatment by LLE in 96-well deep format plate. The optimum separation was carried out in an uncoated $31.2 \mathrm{~cm} \times 75 \mu \mathrm{m}$ fused-silica capillary with an applied voltage of $13 \mathrm{kV}$. The electrophoretic analysis was performed by $50 \mathrm{mM}$ phosphate at $\mathrm{pH} 2.5$. The detection wavelength was $210 \mathrm{~nm}$. Under these optimized conditions, FESI with acetonitrile enhanced the sensitivity of quetiapine about $40-50$ folds in total. The method was suitably validated with respect to stability, specificity, linearity, lower limit of quantitation, accuracy, precision and extraction recovery. Using mirtazapine as an internal standard $(100 \mathrm{ng} / \mathrm{mL})$, the response of quetiapine was linear over the range of $1-1000 \mathrm{ng} / \mathrm{mL}$. The lower limit of quantification was $1 \mathrm{ng} / \mathrm{mL}$. The intra- and inter-day precisions for the assay were within $4.8 \%$ and $12.7 \%$, respectively. The method represents the first application of FESI-CZE to the analysis of quetiapine fumarate in beagle dog plasma after oral administration.
\end{abstract}

Keywords: quetiapine fumarate; capillary zone electrophoresis; field enhanced sample injection

\section{Introduction}

Quetiapine fumarate (QTP), whose chemical name is bis[2-(2-[4-(dibenzo[b, $f][1,4]$ thiazepin11-yl)]ethoxy)ethanol]fumarate, Figure $1 \mathrm{~A}$, is a dibenzothiazepine derivative with an atypical neuropharmacological profile. Studies [1-4] have showed that quetiapine is very effective for negative and positive schizophrenia, as well as cognitive impairment, with slightly choline resistant and rarely granulocytopenia. Due to the highest serotonin/dopamine binding ratio, quetiapine makes the serotonin type $2\left(5-\mathrm{HT}_{2}\right)$-receptor blocking effect about twice as strong as the dopamine $\mathrm{D}_{2}$-receptor blocking effect. As a result of this binding pattern, the extrapyramidal side effects of quetiapine are minimal [3,5-8]. Those characteristics make quetiapine well tolerated and effective in patients who have Alzheimer's disease or Parkinson's disease [3,4]. In addition, quetiapine is metabolized by the CYP450 system, primarily by CYP3A4 enzyme [5,9]. 


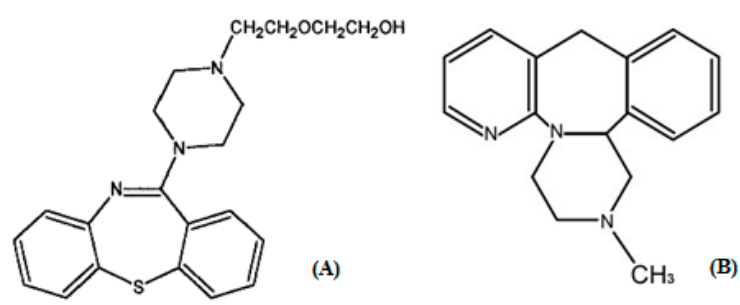

Figure 1. Chemical structures of quetiapine (A) and internal standard mirtazapine (B).

To the best of our knowledge, many methods had been described so far in the literature for the determination of quetiapine, including high-performance liquid chromatography with ultraviolet detection (HPLC-UV) [10-12], UPLC-UV [13], and liquid chromatography coupled with tandem mass spectrometry (LC-MS/MS) [14-16]. The detection limit of UV generally can only reach $\mu \mathrm{g}$ level. HPLC-MS/MS, which is expensive for most laboratories, has been the most common choice for this purpose to date. While the obvious advantages of CE are simplicity, economies, high efficiency, good selectivity, small sample volume, and short analysis time. Moreover, various separation modes can be selected for different analytes. Vincenzo Pucci et al. [17] used a spectrophotometric and CZE method to determinate quetiapine in commercial tablets for the quality control. However, when we used ultraviolet detection, the sensitivity of $\mathrm{CE}$ was always limited because of the little injection volume and small detection window. To resolve this problem, some stacking CE methods were developed to enhance sensitivity [18-21], such as field amplified sample stacking (FASS), field enhanced/amplified sample injection (FESI), dynamic $\mathrm{pH}$ junction or large volume sample stacking (LVSS), and using ionic liquid during pretreatment. In addition, FESI was the easiest sample stacking method by electrokinetic injection that the conductivity of the BGE was at least ten folds than sample due to the simple requirement. However, there was no literature about the quantitative analysis of quetiapine using any stacking CE method until now.

Therefore, the aim of this paper was to develop and validate a simple and rapid CZE method for the determination of quetiapine in beagle dog plasma. For this purpose, a new FESI-CZE method was developed, optimized and validated in terms of precision, linearity, accuracy, robustness, and detection and quantitation limits for determination of quetiapine.

\section{Results and Discussion}

\subsection{Method Development}

In this study, we explored the optimization and validation of preconcentration process and separation mode. Both quetiapine and IS had strong UV absorption at $210 \mathrm{~nm}$. For this reason, the detection wavelength was set at $210 \mathrm{~nm}$.

\subsubsection{Optimization of Buffer Specie and Buffer Concentration and $\mathrm{pH}$ and Voltage}

Because different buffer solutions have different influence on the EOF and the current produced in the capillary, the effects on the separation performance and peak shape was various [22]. At the beginning of this experiment, three different buffers (acetic acid-sodium acetate, formic acid-sodium formate, phosphoric acid-sodium phosphate) were selected to be studied. As was shown in Figure 2, the peak shapes of analytes were pretty good when we used phosphate as electrolyte at this experiment. In CE analysis, the concentration of buffer is very important. If the concentration of electrolyte is too high, the current will be increased and the EOF will be out of shape, leading to more joule heating and longer analysis time. While lower concentration of buffer will decrease the sensitivity of method because of the lower ionic strength. Considering of the effects of electrolyte's concentration and the demand of peak shape, $50 \mathrm{mM}$ phosphate buffer was selected. 
Based on the pKa value (6.8) of quetiapine, measurements were carried out at lower $\mathrm{pH}$ values, which can make quetiapine easily charged, in order to acquire a proper migration time and good resolution of quetiapine and IS. Running buffer contained $50 \mathrm{mM}$ phosphate was studied at different $\mathrm{pH}(2.0-5.0)$ to observe the influence on electrophoretic behavior of quetiapine and IS. Better resolution and analysis time were acquired when $\mathrm{pH}<3.0$, so a running buffer contained $50 \mathrm{mM}$ phosphate with a $\mathrm{pH}$ of 2.5 was selected.

Different separation voltages were also tested, such as 11, 12, 13, 14, and $15 \mathrm{kV}$. While too large separation voltage could cause certain current problems, including high joule heating and low column efficiency. A high column efficiency and short separation time could be obtained when $13 \mathrm{kV}$ was chosen in the experiments.

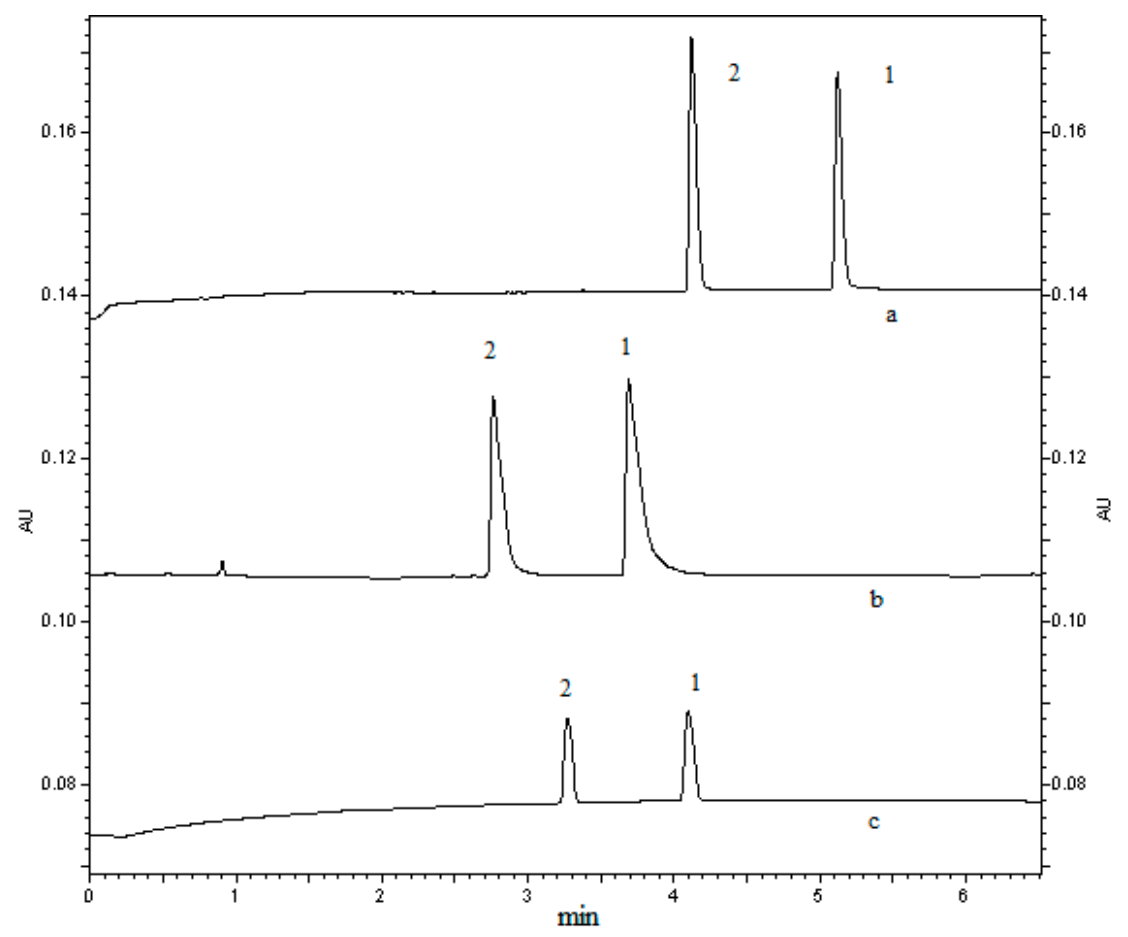

Figure 2. The effect of different buffers on the peak shape of quetiapine fumarate $(1000 \mathrm{ng} / \mathrm{mL})$ standard and IS (1000 ng/mL). Capillary, $31.2 \mathrm{~cm} \times 75 \mu \mathrm{m}$ i.d., effective length $21 \mathrm{~cm}$, uncoated; sample solvents, distilled water; electrokinetic injection, $7.5 \mathrm{kV} \times 10 \mathrm{~s}$; applied voltage, $10 \mathrm{kV}(+) \rightarrow(-)$; column temperature, $25^{\circ} \mathrm{C}$; detection $210 \mathrm{~nm}$. Electropherograms: (a) acetic acid-sodium acetate; (b) formic acid-sodium formate; (c) phosphoric acid-sodium phosphate. Peak 1: quetiapine fumarate; peak 2: IS.

\subsubsection{Selection of Injection Mode and Sample Solvent}

Hydrodynamic injection and electrokinetic injection are two injection modes frequently used in capillary electrophoresis. By the hydrodynamic injection, all components including many endogenous interferences can be easily introduced to the capillary, resulting in some interferences when conducting bio-sample analysis. However, the electrokinetic injection mode could avoid those interference and obtain proper shapes of both quetiapine and IS in our experiments. Besides of this, there were some published reports about eletrokinetic suitable for FESI [23]. Therefore, electrokinetic injection mode was chosen as the optimum.

FESI was usually employed as a simple and efficient technique to enhance the sensitivity in capillary zone electrophoresis $[19,24,25]$. In this study, the compositions of sample solvent $(10 \%$ buffer, distilled water, ACN-distilled water) were investigated. As was shown in Figure 3, ACN-distilled water could be used as sample solvent to improve sensitivity. Then, the ratios of ACN to distilled water $(55 \%, 60 \%, 65 \%, 70 \%, 75 \%)$ were studied to obtain a higher response of quetiapine and IS. It was 
found that the peak of quetiapine decreased and the current would drop to zero when the ratio of $\mathrm{ACN}$ greater than $70 \%$. In the end, $65 \% \mathrm{ACN}$ distilled water was chosen as sample solvent.

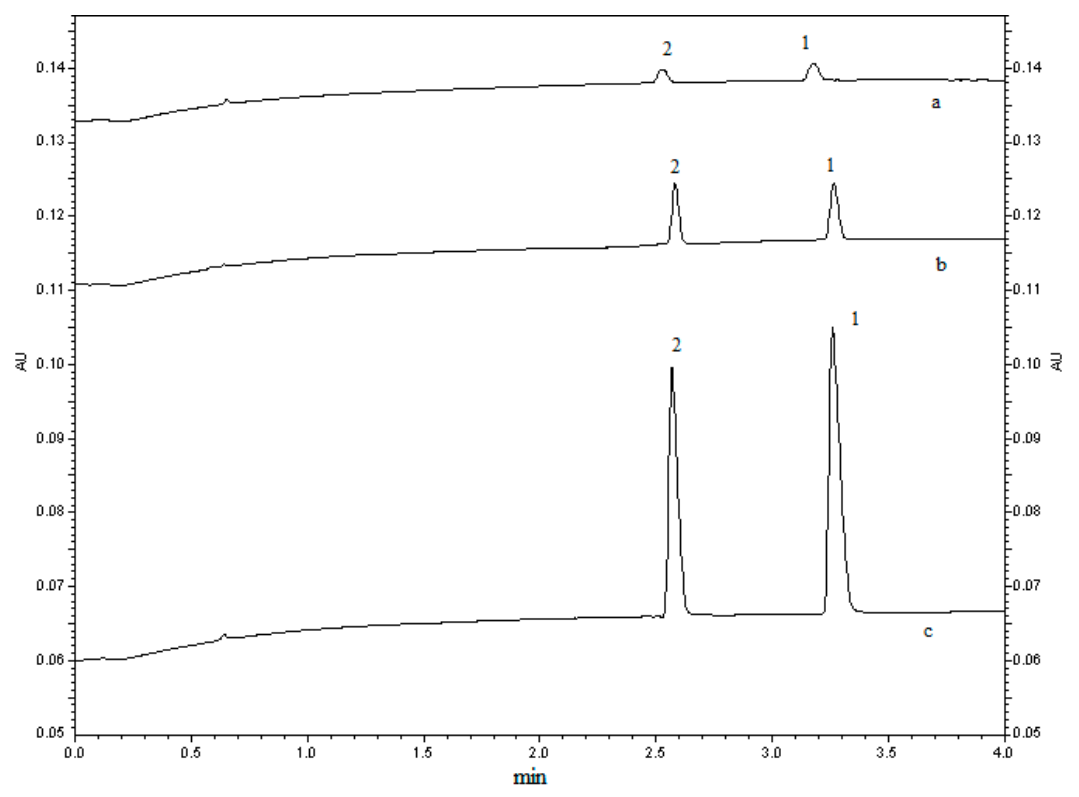

Figure 3. The effect of different sample solvents on FESI of quetiapine fumarate $(1000 \mathrm{ng} / \mathrm{mL})$ standard and IS (1000 ng/mL). Running buffer, $50 \mathrm{mM}$ phosphate ( $\mathrm{pH} 2.5)$; applied voltage, $13 \mathrm{kV}(+) \rightarrow(-)$; electrokinetic injection, $5 \mathrm{kV} \times 10 \mathrm{~s}$. Electropherograms: (a) 10\% buffer; (b) distilled water; (c) $65 \%$ ACN-distilled water. Peak 1: quetiapine fumarate; peak 2: IS.

\subsubsection{Pre-Treatment of Sample}

In this study, two methods of extracting plasma samples were compared. Firstly, protein precipitation, which was very simple and fast, was often used to process plasma samples. However, it was not suitable for quetiapine extraction from plasma due to lower sensitivity and more interference of endogenous components in beagle dog plasma. Then, the liquid-liquid extraction was explored. Increasing the sample volume before extraction and decreasing the volume of redissolve solvent can make the quetiapine and IS concentrated with no interference of endogenous components. In addition, the LLE 96-well deep format plate was used to increase sample throughput and decrease the sample preparation time effectively. Therefore, the liquid-liquid extraction in 96-well deep format plate was chosen as the pre-treatment method.

\subsection{Method Validation}

Analytical method validation was carried out according to the recommendations published by the FDA [26].

\subsubsection{Specificity}

Specificity of the method was investigated by blank plasma, plasma spiked with quetiapine of $1 \mathrm{ng} / \mathrm{mL}$, and a real beagle dog plasma sample to distinguish the analytes from all potentially interfering substances. Peak purity was evaluated by means of the P/ACE System MDQ Software. The total peak purity values of quetiapine fumarate and IS were 1.0000. There were no interfering peaks from the endogenous substances observed at migration times of about $3.4 \mathrm{~min}$ for quetiapine and about $2.6 \mathrm{~min}$ for the IS, which were analyzed under the same optimized condition. Figure 4 showed the typical electropherograms for blank plasma, plasma spiked with quetiapine at $1 \mathrm{ng} / \mathrm{mL}$ (LLOQ) and a test plasma sample. 


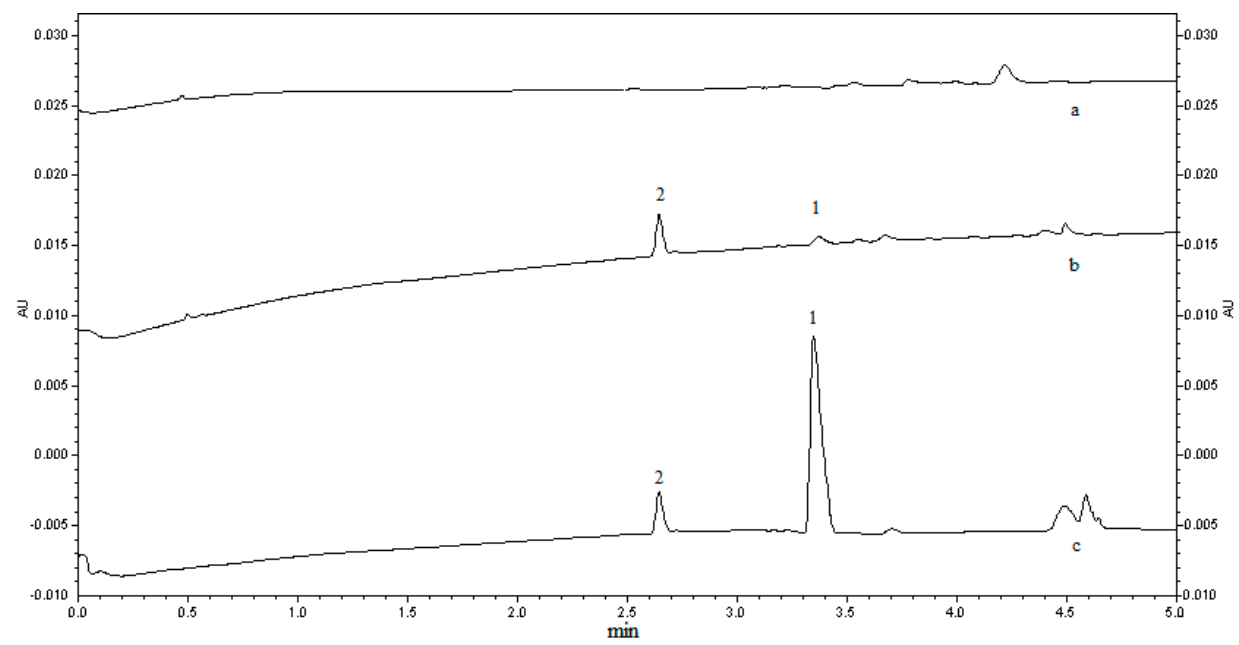

Figure 4. Typical chromatograms of blank plasma (a); blank plasma spiked with $1 \mathrm{ng} / \mathrm{mL}$ (LLOQ) quetiapine fumarate and $100 \mathrm{ng} / \mathrm{mL}$ IS (b); test plasma spiked with $100 \mathrm{ng} / \mathrm{mL}$ IS at $1.5 \mathrm{~h}$ after the dose of $200 \mathrm{mg}$ quetiapine fumarate immediate release tablet (c). Peak 1: quetiapine fumarate; peak 2: IS.

\subsubsection{Linearity of Calibration Curves and Lower Limit of Quantification (LLOQ)}

The linearity of the CZE method was evaluated by analysis of seven concentration samples of quetiapine $(1,2,10,50,200,500$ and $1000 \mathrm{ng} / \mathrm{mL})$, each sample had a concentration of $100 \mathrm{ng} / \mathrm{mL}$ of IS. The calibration equation was $\mathrm{y}=0.02636 \times-0.002533, \mathrm{r}^{2}=0.9968$. In this equation, $\mathrm{y}$ represents the peak area ratios of the analyte to the IS and $x$ represents the plasma concentration of analyte in $\mathrm{ng} / \mathrm{mL}$. The calibration curve was achieved with a $1 / x$ weighing factor. The LLOQ of quetiapine in beagle dog plasma was found to be $1 \mathrm{ng} / \mathrm{mL}$ with accuracy of $95.7 \%$ and precision of $12.7 \%(n=5)$.

\subsubsection{Accuracy, Precision and Extraction Recovery}

Five replicate samples at each QC concentrations (LQC, MQC, and HQC, 2, 50, $800 \mathrm{ng} / \mathrm{mL}$ ) were analyzed in three separate runs. Accuracy was determined by calculating the ratios of the predicted values to the spiked concentrations and the precision was assessed by the relative standard deviations (RSD, \%). The results in Table 1 show that the within- and between-day variances at three QC levels were all below $10.1 \%$. It is shown that the accuracy was from $98.2 \%$ to $107.6 \%$. Recovery from beagle dog plasma samples was evaluated in quintuplicate for three levels of quetiapine, the response for each concentration being compared with that from the corresponding standard solution. The extraction recovery values were shown in Table 2 .

Table 1. Within- and between-run accuracy and precision in spiked plasma samples.

\begin{tabular}{|c|c|c|c|}
\hline Sample Level & Low QC & Medium QC & High QC \\
\hline & $2 \mathrm{ng} / \mathrm{mL}$ & $50 \mathrm{ng} / \mathrm{mL}$ & $800 \mathrm{ng} / \mathrm{mL}$ \\
\hline \multicolumn{4}{|c|}{ Within-run accuracy and precision } \\
\hline \multicolumn{4}{|l|}{ Validation run 1} \\
\hline Mean \pm SD $(n g / m L)$ & $2.12 \pm 0.13$ & $49.63 \pm 3.10$ & $804.65 \pm 43.08$ \\
\hline Accuracy $\pm \mathrm{SD}(\%)$ & $107.6 \pm 6.7$ & $101.0 \pm 6.3$ & $102.3 \pm 5.5$ \\
\hline RSD $(\%)$ & 6.2 & 6.3 & 5.4 \\
\hline $\mathrm{N}$ & 5 & 5 & 5 \\
\hline \multicolumn{4}{|l|}{ Validation run 2} \\
\hline Mean $\pm \mathrm{SD}(\mathrm{ng} / \mathrm{mL})$ & $1.94 \pm 0.20$ & $50.38 \pm 4.55$ & $812.36 \pm 52.30$ \\
\hline Accuracy \pm SD $(\%)$ & $98.2 \pm 9.9$ & $102.5 \pm 9.3$ & $103.3 \pm 6.7$ \\
\hline RSD (\%) & 10.1 & 9.0 & $6 . \overline{4}$ \\
\hline $\mathrm{N}$ & 5 & 5 & 5 \\
\hline
\end{tabular}


Table 1. Cont.

\begin{tabular}{cccc}
\hline Sample Level & Low QC & Medium QC & High QC \\
\hline Validation run 3 & & & \\
Mean \pm SD (ng/mL) & $2.10 \pm 0.15$ & $51.09 \pm 3.34$ & $825.25 \pm 39.85$ \\
Accuracy \pm SD $(\%)$ & $106.9 \pm 7.5$ & $104.0 \pm 6.8$ & $104.9 \pm 5.1$ \\
RSD (\%) & 7.0 & 6.5 & 4.8 \\
N & 5 & 5 & 5 \\
\hline Between-run accuracy and precision & & \\
\hline Mean \pm SD (ng/mL) & $2.05 \pm 0.17$ & $50.36 \pm 3.50$ & $814.09 \pm 42.93$ \\
Accuracy \pm SD $(\%)$ & $104.2 \pm 8.7$ & $102.5 \pm 7.1$ & $103.5 \pm 5.5$ \\
RSD (\%) & 8.4 & 6.9 & 5.3 \\
N & 15 & 15 & 15 \\
\hline
\end{tabular}

Table 2. Recovery values of quetiapine fumarate and IS in spiked plasma samples.

\begin{tabular}{cccc}
\hline Compound & Concentration & Recovery (\%) & RSD (\%) \\
\hline & $(\mathrm{ng} / \mathrm{mL})$ & $($ mean \pm SD) & \\
\hline Quetiapine $(n=5)$ & 2 & $79.5 \pm 9.1$ & 11.4 \\
& 50 & $84.4 \pm 7.3$ & 8.6 \\
IS $(n=15)$ & 800 & $89.9 \pm 4.9$ & 5.5 \\
& 100 & $85.6 \pm 7.6$ & 8.9 \\
\hline
\end{tabular}

\subsubsection{Stability}

The stability of quetiapine in beagle dog plasma was evaluated by analyzing three QC levels in quintuple including short-term temperature stability, long-term stability, autosampler stability and freeze-thaw cycles stability. The stability was evaluated by the mean values and standard deviations of the ratios between the concentration found and initial concentration. The results in Table 3 showed that quetiapine fumarate had an acceptable stability at room temperature for $2 \mathrm{~h}$, at $-20{ }^{\circ} \mathrm{C}$ for 1 month, in the autosampler at room temperature for $8 \mathrm{~h}$ after liquid-liquid extraction and after three freeze-thaw cycles with the values of $94.2 \%-106.3 \%, 96.3 \%-105.0 \%, 98.1 \%-104.4 \%$ and $101.6 \%-105.7 \%$, respectively, at the three studied concentrations. All results of stability tests indicated that the stability of quetiapine over all steps of determination was well good, so the method was proved to be applicable for routine analyses.

Table 3. Stability results of quetiapine fumarate in spiked plasma samples $(n=5)$.

\begin{tabular}{ccccc}
\hline Sample Condition & $\begin{array}{c}\text { Nominal Concentration } \\
(\mathbf{n g} / \mathbf{m L})\end{array}$ & $\begin{array}{c}\text { Measured Concentration } \\
(\mathbf{n g} / \mathbf{m L})(\mathbf{M e a n} \pm \mathbf{S D})\end{array}$ & Accuracy (\%) & RSD (\%) \\
\hline Freeze-thaw stability $^{\mathrm{a}}$ & 2 & $2.04 \pm 0.16$ & 103.7 & 7.7 \\
& 50 & $49.94 \pm 1.25$ & 101.6 & 2.5 \\
30-day stability b & 800 & $831.55 \pm 21.89$ & 105.7 & 2.6 \\
& 2 & $1.89 \pm 0.17$ & 96.3 & 8.9 \\
Bench top stability c & 50 & $51.26 \pm 2.54$ & 104.3 & 5.0 \\
& 800 & $825.86 \pm 39.96$ & 105.0 & 4.8 \\
Autosampler stability $^{\mathrm{d}}$ & 2 & $1.85 \pm 0.14$ & 94.2 & 7.3 \\
& 50 & $51.04 \pm 2.68$ & 103.8 & 5.3 \\
& 800 & $835.51 \pm 29.61$ & 106.3 & 3.5 \\
& 2 & $1.93 \pm 0.21$ & 98.1 & 11.1 \\
\hline
\end{tabular}

${ }^{a}$ : After three freeze-thaw cycles; ${ }^{b}$ : Stored at $-20^{\circ} \mathrm{C}^{c}{ }^{c}$ : Exposed at ambient temperature $\left(25^{\circ} \mathrm{C}\right)$ for $2 \mathrm{~h} ;{ }^{\mathrm{d}}$ : Kept at ambient temperature $\left(25^{\circ} \mathrm{C}\right)$ for $8 \mathrm{~h}$. 


\subsection{Application to Preclinical Pharmacokinetic Study}

The developed and validated FESI-CZE method was used to analyze pharmacokinetic profile of quetiapine fumarate in six beagle dogs, which received a single oral dose of $200 \mathrm{mg}$ of quetiapine fumarate immediate release tablets and sustained release tablets. The sustained release tablet was test formulation. Figure 5 represented mean plasma concentration profile of quetiapine $v s$. time. The pharmacokinetic parameters were analyzed by non-compartmental method using the Bioavailability Program Package (BAPP, China Pharmaceutical University, China). After a single dose administration of quetiapine fumarate immediate release tablets, the $t_{1 / 2}, \mathrm{MRT}, \mathrm{C}_{\max }, T_{\max }, \mathrm{AUC}_{0-24}$ and $\mathrm{AUC}_{0-\infty}$ were $(2.50 \pm 1.21) \mathrm{h},(2.98 \pm 0.43) \mathrm{h}$, $(291.33 \pm 15.19) \mathrm{ng} / \mathrm{mL},(1.42 \pm 0.20) \mathrm{h},(585.39 \pm 110.23) \mathrm{ng} \cdot \mathrm{h} / \mathrm{mL}$ and $(592.26 \pm 109.81) \mathrm{ng} \cdot \mathrm{h} / \mathrm{mL}$, respectively. For compound sustained release tablets, the same pharmacoknetic parameters were $(5.42 \pm 1.18) \mathrm{h},(5.18 \pm 0.42) \mathrm{h},(226.07 \pm 21.38) \mathrm{ng} / \mathrm{mL},(3.00 \pm 0.63) \mathrm{h},(733.46 \pm 82.81) \mathrm{ng} \cdot \mathrm{h} / \mathrm{mL}$ and (750.30 \pm 89.67$) \mathrm{ng} \cdot \mathrm{h} / \mathrm{mL}$, respectively.

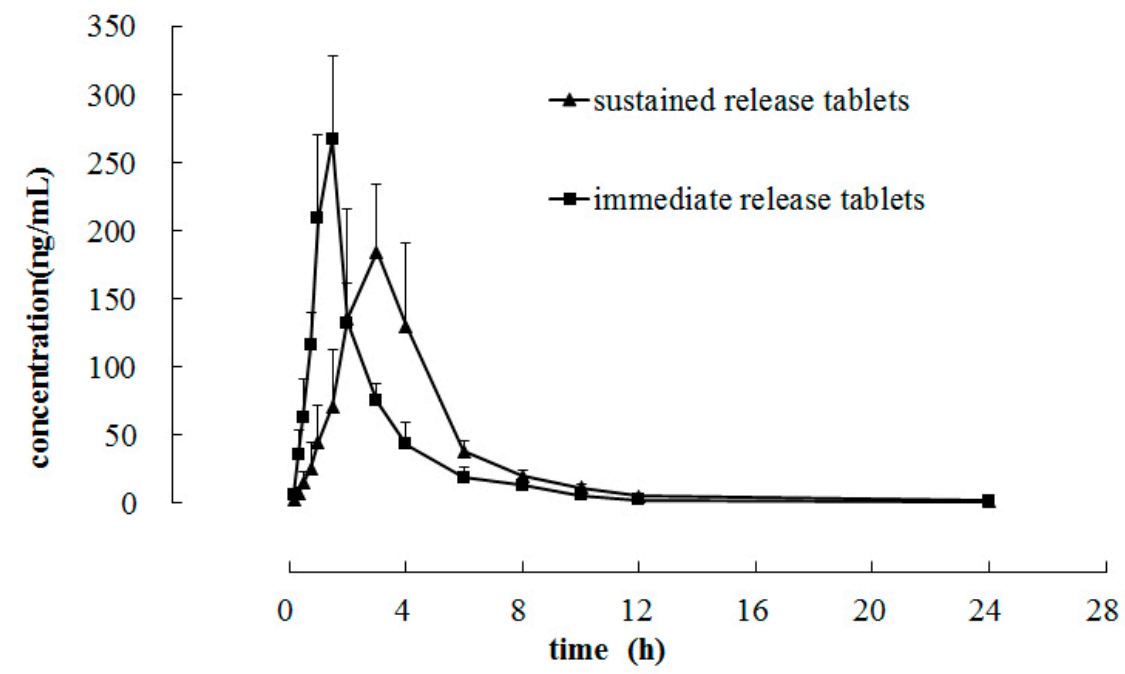

Figure 5. Mean plasma concentration-time curve in six beagle dogs after a single oral dose of $200 \mathrm{mg}$ of quetiapine fumarate immediate release tablets and sustained release tablets.

\section{Experimental Section}

\subsection{Chemicals and Reagents}

Quetiapine fumarate standard reference material (99.9\% purity) was purchased from National Institutes for Food and Drug Control (Beijing, China). The immediate release tablets formulation of quetiapine fumarate $(200 \mathrm{mg}$, lot: KA187) were kindly supplied by AstraZeneca S. p. A. (Basiglio, Milan, Italy). The sustained release tablets formulation of quetiapine fumarate (200 mg, lot: C10125A) also obtained from AstraZeneca S. p. A. Mirtazapine (99.9\% purity) was used as the internal standard (IS, Figure 1B) obtained from Dalian Melon Biological Technology Co. Ltd. (Dalian, China). $\mathrm{NaH}_{2} \mathrm{PO}_{4}$ was obtained from China Medicine (Group) Shanghai Chemical Reagent Corporation (Shanghai, PR China). Phosphoric acid was from Sigma (St. Louis, MO, USA). Methyl alcohol and acetonitrile were from MERK KGaA (Darmstadt, Germany). Methyl tert-butyl ether (chromatographic grade) was from J.T. Baker (Phillipsburg, NJ, USA). All chemicals were analytical grade or better. Beagle dog plasma (sodium heparin as an anticoagulant) was obtained from Shanghai Xingang experiment animal field. Water was deionized and purified by using a Milli-Q system (Millipore, Milford, MA, USA) and was used to prepare all aqueous solutions. 


\subsection{CE Instrumentation}

Analyses were performed on a CE system consisted of a Beckman P/ACE MDQ instrument (Beckman Coulter, Brea, CA, USA) equipped with a photodiode array detection detector (PDA) and P/ACE System MDQ Software. The system of 32-Karat software (Beckman) was used for data acquisition, processing, and analysis. Detection was performed on-column at $210 \mathrm{~nm}$, where quetiapine had the maximum absorption. An uncoated fused-silica capillary $(31.2 \mathrm{~cm} \times 75 \mu \mathrm{m}$ i.d., effective length $21 \mathrm{~cm}$ ) was acquired from Hebei Yongnian Optical Fiber Factory (Hebei, China).

\subsection{Capillary Electrophoretic Conditions}

The phosphate buffer (50 mM, pH 2.5) was used in this study as the background electrolyte (BGE). It was prepared by accurately weighing $0.78 \mathrm{~g}$ of sodium dihydrogen phosphate and thoroughly mixed it with $100 \mathrm{~mL}$ deionized water. Then, the $\mathrm{pH}$ of this buffer was adjusted to 2.5 with phosphoric acid. BGE was prepared freshly every day and filtered through a $0.45 \mu \mathrm{m}$ hydrophilic cellulose membrane filter and degassed by sonication prior to use. The capillary temperature of the optimal separation was maintained at $25^{\circ} \mathrm{C}$ by immersion of the capillary in the cartridge around of circulating cooling liquid. The separation voltage was set at $13 \mathrm{kV}$ with the current of about $98 \mu \mathrm{A}$. The sample was injected by electrokinetic injection modes $(5 \mathrm{kV} \times 10 \mathrm{~s})$. A new capillary was conditioned by rinsed with $1 \mathrm{M} \mathrm{NaOH}$ for $30 \mathrm{~min}$, and then flushed with $0.1 \mathrm{M} \mathrm{NaOH}, \mathrm{H}_{2} \mathrm{O}, 0.1 \mathrm{M} \mathrm{HCl}$ and $\mathrm{H}_{2} \mathrm{O}(15 \mathrm{~min}$ each), sequentially. At the beginning of each working day the capillary was rinsed with $\mathrm{H}_{2} \mathrm{O}(2 \mathrm{~min})$, $0.1 \mathrm{M} \mathrm{NaOH}$ (10 $\mathrm{min}), \mathrm{H}_{2} \mathrm{O}$ (2 min), and running buffer (10 min) in regular sequence. At routine condition between runs, the capillary was rinsed in turn with $0.1 \mathrm{M} \mathrm{NaOH}, 0.1 \mathrm{M} \mathrm{HCl}, \mathrm{H}_{2} \mathrm{O}$ and then BGE, each for $2 \mathrm{~min}$.

\subsection{Preparation of Stock Solutions, Calibration Samples and Quality Control Samples}

Stock solutions of quetiapine fumarate and the IS were prepared in methanol at concentration of $1 \mathrm{mg} / \mathrm{mL}$, respectively. The quetiapine fumarate working standard solutions were prepared daily by diluting the stock solution with distilled water to desired concentration of the range from 0.01 to $10 \mu \mathrm{g} / \mathrm{mL}$. The stock solution of IS was diluted with distilled water to working solution $(1 \mu \mathrm{g} / \mathrm{mL})$. All described solutions were stored at $4{ }^{\circ} \mathrm{C}$.

Calibration samples were obtained by diluting standard working solutions $(10 \mu \mathrm{L})$ with drug-free beagle dog control plasma $(90 \mu \mathrm{L})$, to span a calibration standard range of $1-1000 \mathrm{ng} / \mathrm{mL}(1,2,10$, 50, 200, 500, and $1000 \mathrm{ng} / \mathrm{mL})$. Quality control (QC) samples (2, 50, $800 \mathrm{ng} / \mathrm{mL})$ were independently prepared by spiking appropriate amount of the working standard solutions in drug-free beagle dog control plasma.

\subsection{Extraction Procedure}

Samples were prepared by LLE in 96-well deep format plate ( $2 \mathrm{~mL}$, Corning Life Sciences-Axygen Inc, CA USA) to increase throughput. We used an automatic multichannel electronic pipette (INTEGRA Bioscience AG, Switzerland) to complete liquid transfer steps. Plasma samples were thawed at room temperature after taken out from $-80{ }^{\circ} \mathrm{C}$ freezer. $100 \mu \mathrm{L}$ aliquot of plasma samples were added into 96-well deep format plate. Aliquots of $10 \mu \mathrm{L}$ IS working solution $(1 \mu \mathrm{g} / \mathrm{mL})$ were added and vortexed homogenized for $30 \mathrm{~s}$. The extraction consisted in addition of $500 \mu \mathrm{L}$ methyl tert-butyl ether. Then the mixture was vortex-mixed for $3 \mathrm{~min}$ in a platform and centrifuged at $3000 \mathrm{~g}$ for $10 \mathrm{~min}$. $400 \mu \mathrm{L}$ of the supernatant organic layer was transferred from the original sample plate into a new 96-well deep format plate. And then the plate was evaporated under a gentle nitrogen flow at $30{ }^{\circ} \mathrm{C}$. All dry residues were reconstituted by addition of $20 \mu \mathrm{L}$ acetonitrile-water $(65: 35, v / v)$. Finally, the plate was vortex-mixed for $5 \mathrm{~min}$, then centrifuged for $10 \mathrm{~min}$ at $4000 \mathrm{~g}$. The supernatant was injected into the CZE system. 


\subsection{Pharmacokinetic Study in Beagle Dogs}

This method was applied to determine plasma concentrations of quetiapine fumarate from a preclinical trial in beagle dogs. Beagle dogs were respectively received a single oral dose of $200 \mathrm{mg}$ of quetiapine fumarate immediate release tablet and sustained release tablet. About $1 \mathrm{~mL}$ of blood samples were collected in heparinized centrifuge tubes at before administration ( $0 \mathrm{~min})$ and at the time of 10, 20, 30, $45 \mathrm{~min}$, and 1, 1.5, 2, 3, 4, 6, 8, 10, 12, $24 \mathrm{~h}$ after dosing and centrifuged at $1370 \mathrm{~g}$ for $10 \mathrm{~min}$ to separate the plasma fraction. The obtained plasma samples were stored at $-20{ }^{\circ} \mathrm{C}$ until analysis. The study was approved by a local ethics committee.

\section{Conclusions}

A highly sensitive and effective FESI-CZE method was developed and validated for the determination of quetiapine fumarate in beagle dog plasma, with a sample pretreatment by liquid-liquid extraction in 96-well deep format plate. Under the optimal conditions, this stacking CZE method with electrokinetic injection in combine with dissolving the sample in 65\% ACN yields provided a sensitivity enhancement of about 40-50 folds in comparison with the same sample dissolved in $10 \%$ buffer. The preclinical analysis process and pharmacokinetic parameters confirmed that the CZE method can be an alternative method for routine analysis of quetiapine fumarate in plasma.

Acknowledgments: This work was supported by Shanghai Key Laboratory Fund (Grant No. 14DZ2272700).

Author Contributions: Yuqing Cao preformed the bioanalysis and prepared the manuscript; Jun Wen analyzed data and calculated PK parameters; Guorong Fan and Jun Wen interpreted results of experiments; Guorong Fan and Tingting Zhou designed the whole research. Guorong Fan reviewed the final manuscript and all the authors have read and approved the final version.

Conflicts of Interest: The authors declare no conflict of interest.

\section{References}

1. Heres, S.; Davis, J.; Maino, K.; Jetzinger, E.; Kissling, W.; Leucht, S. Why Olanzapine Beats Risperidone, Risperidone Beats Quetiapine, and Quetiapine Beats Olanzapine An Exploratory Analysis of Head-to-Head Comparison Studies of Second-Generation Antipsychotics. Am. J. Psychiatry 2006, 163, 185-194. [CrossRef] [PubMed]

2. Dettlin, M.; Anghelescu, I.-G. Antipsychotic Drugs and Schizophrenia. N. Engl. J. Med. 2006, 354, $298-300$.

3. Arvanitis, L.A.; Miller, B.G. Multiple fixed doses of "Seroquel" (quetiapine) in patients with acute exacerbation of schizophrenia: A comparison with haloperidol and placebo. Soc. Biol. Psychiatry 1997, 42, 233-246. [CrossRef]

4. Peuskens, J.; Link, C.G.G. A comparison of quetiapine and chlorpromazine in the treatment of schizophrenia. Acta Psychiatr. Scand. 1997, 96, 265-273. [CrossRef] [PubMed]

5. DeVane, C.L.; Nemeroff, C.B. Clinical Pharmacokinetics of Quetiapine: An Atypical Antipsychotic. Clin. Pharmacokinet. 2001, 40, 509-522. [CrossRef] [PubMed]

6. Jensen, N.H.; Rodriguiz, R.M.; Caron, M.G.; Wetsel, W.C.; Rothman, R.B.; Roth, B.L. N-Desalkylquetiapine, a Potent orepinephrine Reuptake Inhibitor and Partial 5-HT1A Agonist, as a Putative Mediator of Quetiapine's Antidepressant Activity. Neuropsychopharmacology 2008, 33, 2303-2312. [CrossRef] [PubMed]

7. Baune, B.T. New developments in the management of major depressive disorder and generalized anxiety disorder role of quetiapine. Neuropsychiatric Dis. Treat. 2008, 4, 1181-1192. [CrossRef]

8. Wetzel, H.; Szegedi, A.; Hain, C.; Wiesner, J.; Schlegel, S.; Benkert, O. Seroquel (ICl 204 636), a putative atypical antipsychotic, in schizophrenia with positive symptomatology results of an open clinical trial and changes of neuroendocrinological and EEG parameters. Psychopharmacology 1995, 119, 231-238. [CrossRef] [PubMed]

9. Prior, T.I.; Chue, P.S.; Tibbo, P.; Baker, G.B. Drug metabolism and atypical antipsychotics. Eur. Neuropsychopharmacol. 1999, 9, 301-309. [CrossRef] 
10. Sachse, J.; Köller, J.; artter, S.H.; Hiemke, C. Automated analysis of quetiapine and other antipsychotic drugs in human blood by high performance-liquid chromatography with column-switching and spectrophotometric detection. J. Chromatogr. B 2006, 830, 342-348. [CrossRef] [PubMed]

11. Mercolini, L.; Grillo, M.; Bartoletti, C.; Boncompagni, G.; Raggi, M.A. Simultaneous analysis of classical neuroleptics, atypical antipsychotics and their metabolites in human plasma. Anal. Bioanal. Chem. 2007, 388, 235-243. [CrossRef] [PubMed]

12. Saracino, M.A.; Mercolini, L.; Flotta, G.; Albers, L.J.; Merli, R.; Raggi, M.A. Simultaneous determination of fluvoxamine isomers and quetiapine in human plasma by means of high-performance liquid chromatography. J. Chromatogr. B 2006, 843, 227-233. [CrossRef] [PubMed]

13. Trivedi, R.K.; Patel, M.C. Development and Validation of a Stability Indicating RP-UPLC Method for Determination of Quetiapine in Pharmaceutical Dosage Form. Sci. Pharm. 2011, 79, 97-111. [CrossRef] [PubMed]

14. Davis, P.C.; Bravob, O.; Gehrke, M.; Azumaya, C.T. Development and validation of an LC-MS/MS method for the determination of quetiapine and four related metabolites in human plasma. J. Pharm. Biomed. Anal. 2010, 51, 1113-1119. [CrossRef] [PubMed]

15. Fisher, D.S.; Partridge, S.J.; Handley, S.A.; Couchman, L.; Morgan, P.E.; Flanagan, R.J. LC-MS/MS of someatypicalantipsychotics inhumanplasma, serum, oralfluid and haemolysed whole blood. Forensic Sci. Int. 2013, 229, 145-150. [CrossRef] [PubMed]

16. Barrett, B.; capek, M.H.; Huclováa, J.; Bořek-Dohalskýa, V.; Fejta, P.; Němeca, B.; Jelínekc, I. Validated HPLC-MS/MS method for determination of quetiapine in human plasma. J. Pharm. Biomed. Anal. 2007, 44, 498-505. [CrossRef] [PubMed]

17. Pucci, V.; Mandrioli, R.; Ferranti, A.; Furlanetto, S.; Raggia, M.A. Quality control of commercial tablets containing the novel antipsychotic quetiapine. J. Pharm. Biomed. Anal. 2003, 32, 1037-1044. [CrossRef]

18. Wang, Y.-R.; Yang, Y.-H.; Lu, C.-Y.; Lin, S.-J.; Chen, S.-H. Trace analysis of acetylcholinesterase inhibitors with antipsychotic drugs for Alzheimer's disease by capillary electrophoresis with on column field-amplified sample injection. Anal. Bioanal. Chem. 2013, 405, 3233-3242. [CrossRef] [PubMed]

19. Breadmore, M.C.; Tubaon, R.M.; Shallan, A.I.; Phung, S.C.; Keyon, A.S.A.; Gstoettenmayr, D.; Prapatpong, P.; Alhusban, A.A.; Ranjbar, L.; See, H.H.; et al. Recent advances in enhancing the sensitivity of electrophoresis and electrochromatography in capillaries and microchips (2012-2014). Electrophoresis 2015, 36, 36-61. [CrossRef] [PubMed]

20. Simpson, S.L., Jr.; Quirino, J.P.; Terabe, S. On-line sample preconcentration in capillary electrophoresis Fundamentals and applications. J. Chromatogr. A 2008, 1184, 504-541. [CrossRef] [PubMed]

21. Breadmore, M.C. Ionic liquid-based liquid phase microextraction with direct injection for capillary electrophoresis. J. Chromatogr. A 2011, 1218, 1347-1352. [CrossRef] [PubMed]

22. Quirino, J.P.; Terabe, S. Approaching a Million-Fold Sensitivity Increase in Capillary Electrophoresis with Direct Ultraviolet Detection Cation-Selective Exhaustive Injection and Sweeping. Anal. Chem. 2000, 72, 1023-1030. [CrossRef] [PubMed]

23. Krivácsy, Z.; Gelencsér, A.; Hlavay, J.; Kiss, G.; Sárvári, Z. Electrokinetic injection in capillary electrophoresis and its application to the analysis of inorganic compounds. J. Chromatogr. A 1999, 834, 21-44. [CrossRef]

24. Quirino, J.P.; Terabe, S. Sample stacking of cationic and anionic analytes in capillary electrophoresis. J. Chromatogr. A 2000, 902, 119-135. [CrossRef]

25. Li, J.; Bi, Y.; Wang, L.; Sun, F.; Chen, Z.; Xu, G.; Fan, G. $\beta$-Cyclodextrin enhanced on-line organic solvent field-amplified sample stacking in capillary zone electrophoresis for analysis of ambroxol in human plasma, following liquid-liquid extraction in the 96-well format. J. Pharm. Biomed. Anal. 2012, 66, 218-224. [CrossRef] [PubMed]

26. US Food and Drug Administration (FDA). Bioanalytical Method Validation. Guidance for Industry, Center for Drug Evaluation and Research (CDER), Center for Veternary Medicine (CVM); FDA: Maryland, MD, USA, 2001.

Sample Availability: Samples of Quetiapine Fumarate are available from the authors.

(C) 2016 by the authors; licensee MDPI, Basel, Switzerland. This article is an open access article distributed under the terms and conditions of the Creative Commons by Attribution (CC-BY) license (http://creativecommons.org/licenses/by/4.0/). 